Int. J. Dev. Biol. 59: 425-433 (2015)

doi: $10.1387 / \mathrm{ijdb} .150137 \mathrm{db}$

\title{
T-cell internal antigen 1 counteracts somatic RNA degradation during early Xenopus embryogenesis
}

\author{
DIANA BAUERMEISTER, MAIKE CLAUßEN* and TOMAS PIELER* \\ Institute of Developmental Biochemistry, Göttingen Center for Molecular Biosciences (GZMB), \\ University of Göttingen, Göttingen, Germany
}

\begin{abstract}
In Xenopus laevis, maternal transcripts that localize to the vegetal cortex of the oocyte are specifically inherited by prospective germ cells during cleavage stages. While a large fraction of maternal transcripts is degraded during the maternal to zygotic transition (MZT), transcripts associated with the germ-line are stable. A sequence in the dead end 13 'UTR mediates vegetal localization in the oocyte as well as miR mediated clearance in somatic cells and germ cell specific stabilization during the MZT in embryos. We could identify Tia1 to co-precipitate with known components of vegetal localization RNPs in X. laevis oocytes. Tia1 interacts and co-localizes with various localization elements from vegetally localizing RNAs. In $X$. laevis embryos, ectopic expression of Tia1 counteracts somatic degradation of $d n d 1$ localization element reporter RNAs and it can synergize with Dnd1 protein in reporter RNA stabilization. Ectopic Tia1 also protects several endogenous localizing and germ cell specific mRNAs from somatic degradation. Thus, proteins that protect germ-line transcripts from miR mediated decay during the MZT in embryos might bind these RNAs already in the oocyte.
\end{abstract}

KEY WORDS: primordial germ cell, microRNA, RNA localization, vegetal, germline

\section{Introduction}

The earliest stages of animal embryogenesis are under the control of maternal determinants. During the maternal to zygotic transition (MZT), the control of embryonic development shifts from maternally provided materials to RNA and proteins produced upon zygotic activation of transcription. This transition also involves the degradation of a large fraction of maternal mRNAs (reviewed in Tadros and Lipshitz, 2009; Langley et al., 2014). In zebrafish, Drosophila and Xenopus, this degradation of maternal mRNAs is mediated by microRNAs (miR) (Giraldez et al., 2006; Bushati et al., 2008; Lund et al., 2009).

Several germline specific mRNAs have been demonstrated to localize to the vegetal cortex during early phases of $X$. laevis oogenesis, some of these becoming part of the germ plasm (reviewed in King et al., 2005). During early cleavage stages, the germ cell precursor cell lineage segregates from somatic cell lineages by selective inheritance of the germ plasm (reviewed in Zhou and King, 2004). Maternally provided $d n d 1$ is an important regulator of germ cell development. It is however not restricted to the germ plasm. During mid-oogenesis, $X$. laevis dnd1 mRNA localizes in a broad region of the vegetal cortex, nevertheless overlapping with the germ plasm (Horvay et al., 2006). Several proteins have been identified to mediate vegetal RNAlocalization during mid-oogenesis; they include lgf2bp3 (Havin et al., 1998), Ptbp1 (Cote et al., 1999), Stau1 (Yoon and Mowry, 2004), Hnrnpab (Czaplinski et al., 2005), Elavl1/2 (Arthur et al., 2009) and Celf1 (Bauermeister et al., 2015). During embryogenesis, $d n d 1$ then becomes specifically restricted to the germ cells, where the Dnd1 protein is required for germ cell migration and survival (Horvay et al., 2006). The restriction of $d n d 1$ transcripts to the germ cells is at least in part a consequence of their miR-18 mediated degradation in the soma during MZT. The

Abbreviations used in this paper: dnd1, dead end 1; EMSA, electrophoretic mobility shift assay; GFP, green fluorescent protein; $\mathrm{K}_{\mathrm{D}}$, dissociation constant; mut, mutant; LE, localization element; miR, microRNA; MZT, maternal to zygotic transition; RBP, RNA binding protein; RNP, ribonucleoprotein; RRM, RNA recognition motif; Tial, T-cell internal antigen 1; UTR, untranslated region; wt, wild-type.

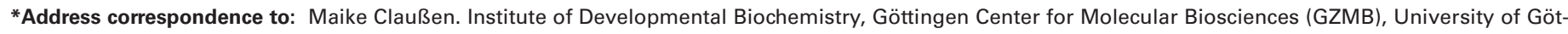
tingen, D-37077 Göttingen, Germany.Tel: +495-5139-5970. E-mail: mclauss1@gwdg.de or

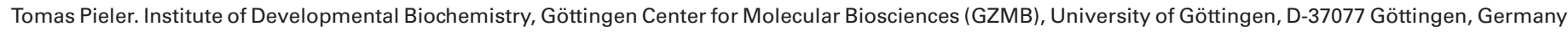
Tel: +495-51391-4613. E-mail: tpieler@gwdg.de

Supplementary Material (2 figures +4 tables) for this paper is available at: http://dx.doi.org/10.1387/ijdb.150137db

Accepted: 10 September 2015.

ISSN: Online 1696-3547, Print 0214-6282 
sequence critical for somatic degradation of $d n d 1$ is located in its 3'UTR and it overlaps with the one that mediates its vegetal localization in the oocyte, hence referred to as localization element (LE) (Horvay et al., 2006; Koebernick et al., 2010).

Protein binding of Elavl2 to the dnd1-LE can promote vegetal localization in the oocyte as well as stability of dnd1 mRNA in the early embryo (Arthur et al., 2009; Koebernick et al., 2010). The Dnd1 protein itself also appears to function in the stabilization of germ cell specific RNAs including its own mRNA. In the zebrafish, Dnd1 was previously demonstrated to serve a critical function in stabilizing the germ cell specific nanos and tdrd7 mRNAs by preventing its miRNA mediated degradation (Kedde et al., 2007). Similarly, in the frog, Dnd1 was demonstrated to cooperate with Elavl2 in protecting its own mRNA from miR mediated degradation in the early embryo (Koebernick et al., 2010).

Here we report on the identification of Tia1 ( $T$ cell internal antigen-1) as an additional protein that is likely be part of the vegetal localization machinery on the one hand and involved in RNA protection against miR mediated degradation at MZT on the other. Tia1 was identified in the context of an attempt aiming at the identification of novel dnd1-LE binding proteins in X. laevisoocytes, making use of an RNA affinity purification approach (Bauermeister et al., 2015). Our results reveal that, in $X$. laevis oocytes, Tia1 is part of one and the same RNP complex together with other proteins known to function in vegetal RNA localization. Tia1 co-localizes with granules containing vegetally localizing RNA. During MZT, overexpression of Tia1 results in the stabilization of a specific subset of vegetally localizing mRNAs, also including the dnd1 mRNA. Moreover, ectopic Tia1 can synergize with ectopic Dnd1 protein in RNA stabilization. These findings suggest that miRNA mediated RNA turnover during $\mathrm{MZT}$ is at least in part regulated by proteins that bind their target RNAs already during vegetal RNA localization in $X$. laevis oocytes.

\section{Results}

Tia1 is a novel candidate component of vegetal RNA localization complexes in Xenopus oocytes

Using an RNP reconstitution/purification approach combined with tandem mass spectrometry (Bauermeister et al., 2015), we identified $X$. laevis Tia1 as one of the proteins that specifically interact with the LE of the vegetally localizing dnd1 mRNA using extracts from stage III/IV oocytes. Tia1 and the highly similar Tiar (Tia-related) represent the TIA-1 family of ARE (AU-rich element) binding proteins (Dember et al., 1996). Both proteins possess three RNA recognition motifs (RRM) in their amino terminus as well as a glutamine-rich domain in their carboxy-terminus. In mice and humans, two isoforms of Tia1 are generated by alternative splicing, referred to as Tia1a (43 kDa) and Tia1b (40 kDa). Tia1a carries an insertion of 11 amino acids within its RRM2 (Beck et al., 1996). We cloned the $X$. laevis ortholog of Tia1a, and this isoform was utilized in all subsequent experiments; it is referred to as Tia1 in the context of this study.

In order to test for a potential incorporation of Tia1 in vegetally localizing RNPs in X. laevis oocytes, a Flag-tagged version of Tia1 was overexpressed in localization competent stage III/IV oocytes and immunoprecipitated (Fig. 1). Celf1 and Ptbp1 were previously shown to be components of localization RNPs in $X$. laevis oocytes and served as controls (Bauermeister et al., 2015; Cote et al., 1999). Tia1 co-precipitates other known localization components such as Igf2bp3, Stau1, Hnrnpab and Elav-like proteins, indicating that Tia1 could indeed be a component of vegetal localization RNP complexes in $X$. laevis oocytes. The co-precipitation of these proteins is sensitive to RNAse treatment, suggesting that their interactions depend on an intact RNA scaffold.

\section{Tia1 is a predominantly cytoplasmic protein that co-localizes} with the dnd1-LE at the vegetal cortex of Xenopus oocytes

Endogenous Tia1 was detected in oocyte and embryonic extracts using a polyclonal $\alpha$-Tia1 antibody, which was previously shown to detect both murine isoforms of TIA1 but not TIAR (Dixon et al., 2003). We detect both isoforms of Tia1 throughout $X$. laevis oogenesis and embryonic development with highest protein levels in later stages of oogenesis and embryonic development (Fig. 2A). Tia1 was shown to shuttle between nucleus and cytoplasm in mammalian tissue culture cells (Zhang et al., 2005). In X. laevis stage VI oocytes, Tia1 was only detected in the cytoplasm (Colegrove-Otero et al., 2005). We detect Tia1 mainly in the cytoplasm throughout oogenesis, with traces of Tia1 in the nucleus of later stage oocytes (Fig. 2B). For the two proteins employed as controls, Igf2bp3 had been demonstrated to be predominantly cytoplasmic (Loeber et al., 2010) and Hnrnpab to be present in both nuclear and cytoplasmic fractions (Czaplinski et al., 2005).

In order to further analyze the subcellular distribution of Tia1,

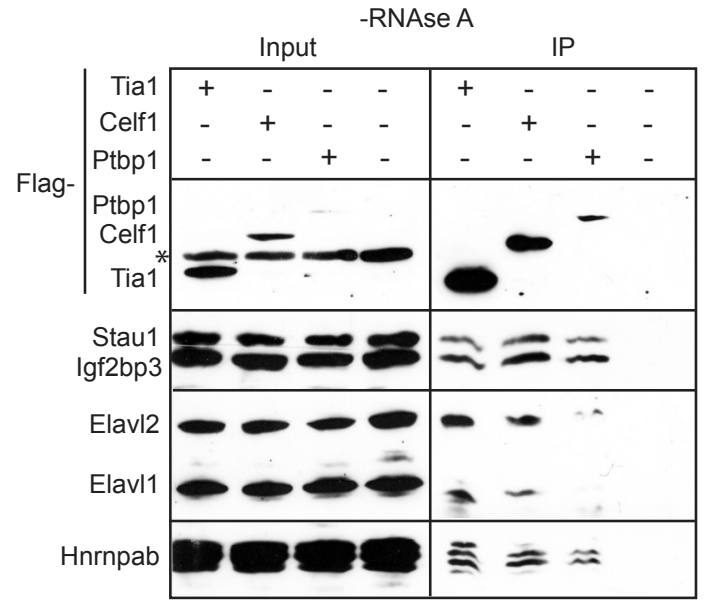

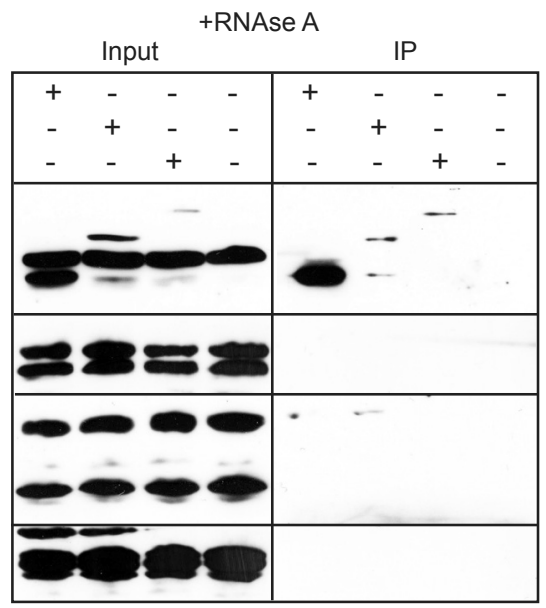

Fig 1. Tia1 co-precipitates known localization RNP complex components in Xenopus oocytes. Flag-tagged versions of different localization proteins and Tia1 were expressed in Xenopus oocytes by means of RNA microinjection and analyzed by Western blot for co-precipitation of known localization factors in the absence or presence of RNase A. Celf1 and Ptbp 1 served as controls for known localization complex components. Immunoprecipitation with extract from uninjected oocytes served as a negative control. The asterisk indicates an unspecific signal caused by cross-reaction of the anti-Flag antibody. 
immunostaining of albino stage III oocytes injected with Cy3-dnd1LE RNA was performed. As reported before (Bauermeister et al., 2015), Cy3-dnd1-LE becomes enriched at the vegetal cortex and in granular structures in the cytoplasm of the vegetal hemisphere (Fig. 2C). Endogenous Tia1 co-localizes with Cy3-dnd1-LE at the vegetal cortex and in the vegetally located granular structures (Fig. 2C). In summary, Tia1 is predominantly cytoplasmic throughout oogenesis and it is enriched at the vegetal cortex, co-localizing with the dnd1-LE.

\section{Tia1 directly interacts with vegetal LEs and binding to the dnd1-LE requires an $A U$-rich region}

Tia1 was identified by an RNA affinity approach using the dnd1-LE (Bauermeister et al., 2015). In order to analyze if Tia1 directly binds to the dnd1-LE and/or to other vegetal LEs, an in vitro interaction assay was performed. In vitro translated Flag-Tia1 (Fig. S1A) was incubated with different Cy3-labeled LE RNAs followed by an antiFlag-co-immunoprecipitation. Tia1 interacts with the dnd1-LE and not with the velo1-LE nor with the $\beta$-globin-3'UTR; weak interaction was detected with the gdf1-LE and the grip2-LE (Fig. 3A). Celf1

A

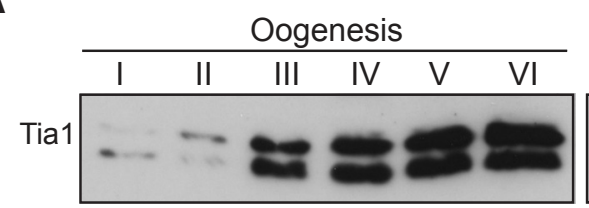

\begin{tabular}{|c|c|c|c|c|c|}
\hline \multirow[b]{2}{*}{$\mathrm{E}$} & \multicolumn{5}{|c|}{ Embryonic development } \\
\hline & $2 / 4$ & 9 & 12 & 22 & 30 \\
\hline
\end{tabular}

B

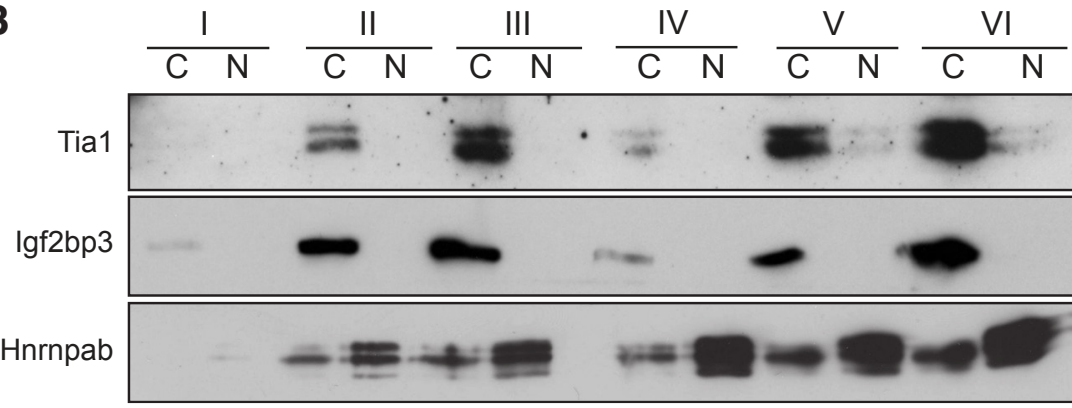

C
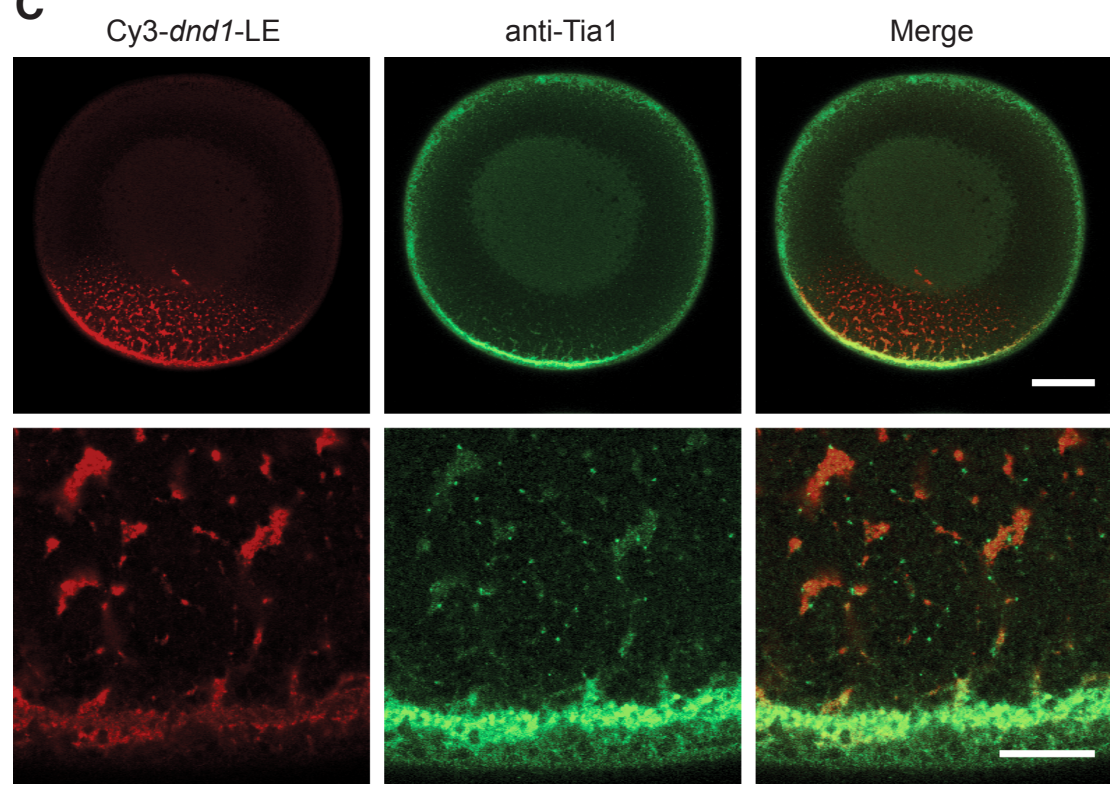

and Ptbp1 served as controls, as they are known to interact with the dnd1-LE as well as with the grip2-LE, and the latter protein also with the gdf1-LE (Fig. 3A; Bauermeister et al., 2015).

In order to determine the region critical for Tia1 interaction within the dnd1-LE, we used in vitrotranslated Flag-Tia1 (Fig. S1 B,C) and Cy3-labeled full length or 5'- and 3'- truncated fragments derived from the dnd1-LE (Fig. 3B). A loss of Tia1 binding is observed with deletions beyond nucleotide 40 (5'del2) of the dnd1-LE, while 3 deletions up to nucleotide 106 (3'del5) maintain binding to Tia1 (Fig. $3 \mathrm{~B})$. Thus, the region critical for Tia1 binding is located between nucleotides 40-106 (Fig. 3B).

Tia1 was previously shown to bind to AU-rich elements (ARE) (Dember et al., 1996; Piecyk et al., 2000; López de Silanes et al., 2005). The Tia1 binding region in the dnd1-LE exhibits AREs composed of several adenines embedded in uracil-rich stretches (Fig. 4A). In order to create a mutant version of the dnd1-LE that is deficient in Tia1 binding, several uracil bases $(U)$ were substituted for adenine bases $(A)$, while the miR-18 binding site is maintained (Fig. 4A). Since the 5'del1 truncated dnd1-LE fragment shows full vegetal localization activity in $X$. laevis oocytes (data not shown), the effect of $A$ to $U$ point mutations on Tia1 binding was analyzed using this 232 nucleotide long dnd1-LE fragment (Fig. 3B, 4B). Binding of Tia1 to wild-type and mutated dnd1-LEs was analyzed by electrophoretic mobility shift assays (EMSA) using bacterially expressed Tia1 and Cy3-labeled RNAs (Fig. S2A, B, 4B). Binding of Tia1 to the mutant dnd1-LE is reduced in comparison to the wild-type dnd1-LE, with a dissociation constant $\left(\mathrm{K}_{\mathrm{D}}\right)$ that is approximately 5 fold increased (Fig. 4B), while high affinity binding of Elavl2 was maintained; however, although mutant $d n d 1$-LE is reduced considerably in binding to Tia1, it shows full localization capacity when injected into oocytes (data not shown). Thus, a possible function of Tia1 in the context of vegetal RNA localization remains to be demonstrated.

\section{Ectopic expression of Tia1 leads to stabilization of Tia1 binding RNAs during early embryogen- esis}

In previous studies, we have reported that Elavl proteins, which are components of vegetal localization RNPs in oocytes, counteract miR mediated

Fig 2. Tia1 is predominantly cytoplasmic and colocalizes with dnd1-LE-RNA at the vegetal cortex in Xenopus oocytes. (A) Temporal analysis of Tia 1 expression during Xenopus oogenesis and embryogenesis. Western blot analysis of Tia1 with equivalent amounts of oocyte and embryonic extracts; stages of oogenesis and embryogenesis were as indicated. (B) Western blot analysis of Tia 1 with cytoplasmic $(\mathrm{C})$ and nuclear $(\mathrm{N})$ fractions from staged oocytes. Igf2bp3 served as control for a cytoplasmic protein and Hnrnpab was utilized as control for a predominantly nuclear protein. (C) Co-localization analysis of endogenous Tia 1 protein and vegetally localizing, microinjected Cy3-dnd1-LE in Xenopus oocytes. Tia immunostaining was performed on Cy3-dnd1-LE RNA injected stage III oocytes. Scale bars indicate $100 \mu \mathrm{m}$ (whole oocyte) and 20 um (magnification). 
degradation of the dnd1-LE during MZT in $X$. laevis embryos (Arthur et al., 2009; Koebernick et al., 2010). In order to analyze if Tia1 carries a similar function in dnd1 mRNA protection, wild-type and mutant dnd1-LE reporter RNAs were injected into 2-cell stage embryos and RNA levels were detected by whole mount in situ hybridization in stage 32-34 (Fig. 5A). Both wild-type and mutant dnd1-LE-reporter RNAs are degraded in somatic cells during MZT but are stable in PGCs (Fig. 5B, C). However, ectopic expression of Tia1 leads to somatic stabilization of wild-type dnd1-LE, but not of the mutant $d n d 1$-LE-reporter RNA that is reduced in Tia1 binding (Fig. 5B, 5C), suggesting that somatic stabilization of wild-type dnd1-LE-reporter RNA during MZT involves Tia1 binding. Although mutations in the dnd1-LE reporter RNA that result in moderately or highly impaired Elavl2 binding lead to its global destabilization (Köbernick et al., 2010), the mutant dnd1-LE utilized in this study, which is defective in Tia1-binding but maintains high affinity Elavl2binding, is stable in PGCs (Fig. 5). This result indicates that, while Tia1-binding is not essential, Elavl2-binding could be sufficient for the stabilization of $d n d 1$-LE reporter RNA in PGCs.

A

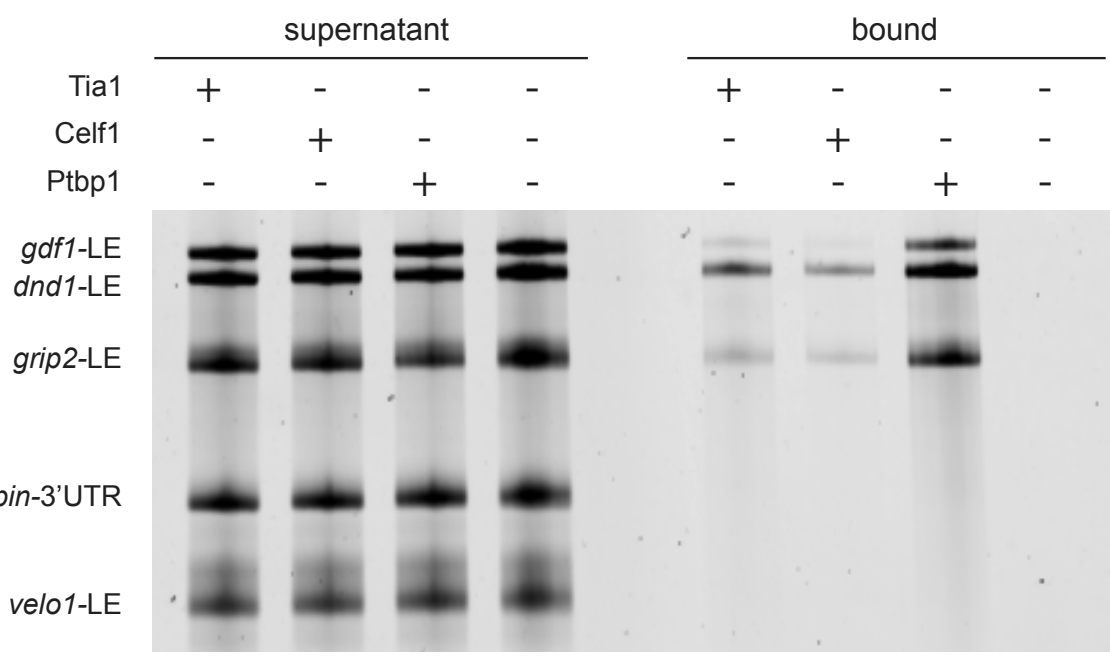

B

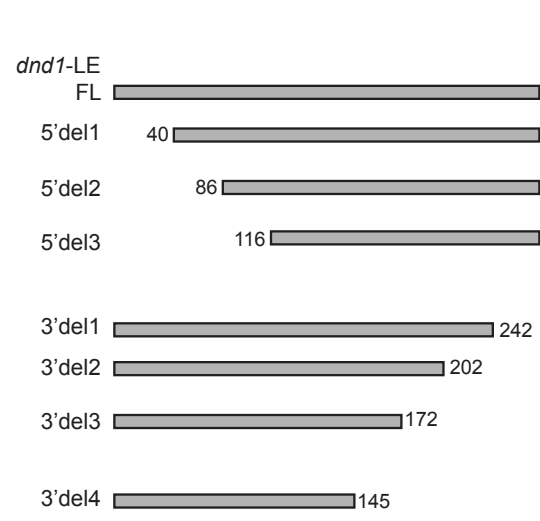

3'del5 106

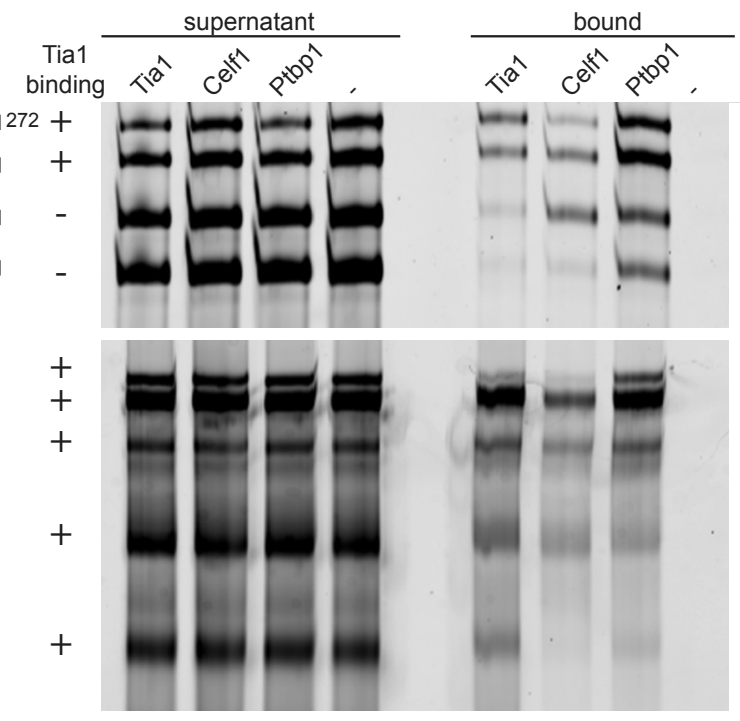

Next, we analyzed if endogenous dnd1 mRNA and/or other localizing mRNAs are stabilized by ectopic expression of Tia1. Two different concentrations of tia1 mRNAwere injected into 2-cell stage embryos and total RNA was extracted just before MZT (stage 8), during MZT (stage 11) and after MZT (stage 14). Different localizing mRNAs (dnd1, grip2, germes and gdf1) show increased RNAlevels during or after MZT, but not before MZT, in tia1 injected embryos in a dose dependent manner (Fig. 5D). Other localizing mRNAs (velo1, pgat, trim36), the non-localizing miR target RNA ccnb2 (Lund et al., 2009) as well as a housekeeping gene (g6dph) are not affected by Tia1 overexpression (Fig. 5D). With the exception of gdf1 mRNA, stabilized mRNAs are germ cell specific (germes, dnd1 and grip2). Thus, Tia1 seems to be involved in stabilization of several, but not all vegetally localizing mRNAs during MZT.

\section{Tia1 and Dnd1 proteins synergize in the somatic stabilization of dnd1-LE RNA}

As described previously (Rothé et al., 2006), we detect tia1 expression mainly in neural tissues of $X$. laevis embryos, but not enriched in PGCs. However, RNA sequencing analyses had revealed that tia1 transcripts are present in $X$. laevis PGCs (our own unpublished results). This raises the question as to how Tia1 mediates protection of germlinespecific mRNAs. We could show earlier that Elavl2 and Dnd1 cooperate in stabilizing dnd 1 mRNA (Koebernick et al., 2010). To test if Tia1 and Dnd1 might also act synergistically, we co-injected suboptimal doses of RNA encoding for either protein into embryos and analyzed dnd1-LE reporter RNA stability by WMISH (Fig. 6A, B). Ectopic expression of Tia1 or Dnd1 proteins in these low amounts leads to weak or no stabilization of $d n d 1$-LE reporter RNA, while co-expression of both proteins leads to robustly increased dnd1-LE reporter RNA levels (Fig. 6A, B). Thus, Tia1 and Dnd1 proteins might synergize in protecting germline RNAs from miR mediated decay.

In summary, our results suggest that

Fig 3 . Tia 1 binds to the $5^{\prime}$ region of the dnd1-LE. (A) In vitro interaction of Flagtagged Tia1 with different LE RNAs. Cy3labeled LE RNAs and $\beta$-globin-3'UTR control RNA were co-immunoprecipitated with Flag-tagged, in vitro translatedTia 1, Celf1 or Ptbp1. Non-programmed reticulocyte lysate served as a negative control (-). Supernatant and bound RNAs were separated by UREAPAGE and detected by fluorescence imaging. (B) In vitro interactions of Flag-tagged Tia 1 with Cy3-labeled full length (FL) and 5'-or 3'-deleted fragments of the dnd1-LE RNA. The region critical for Tia1 binding is marked in light grey (nt 40-106). 


\section{A}

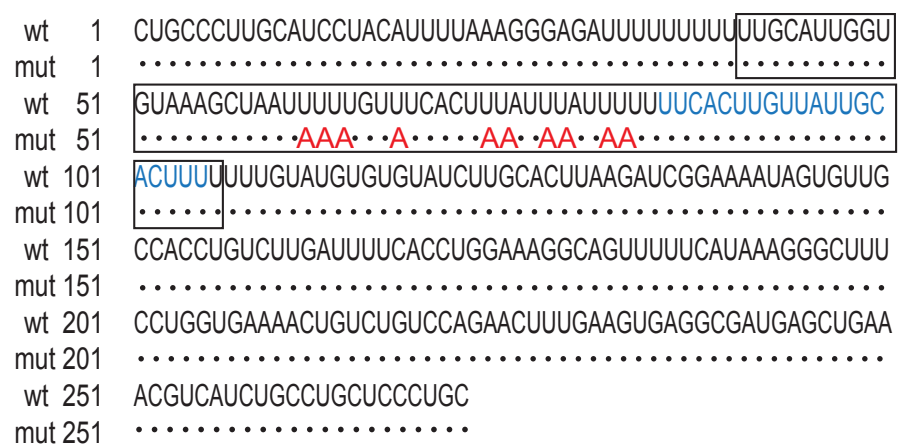

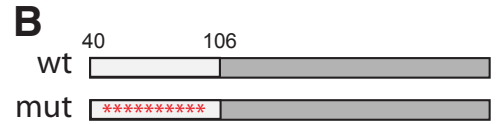

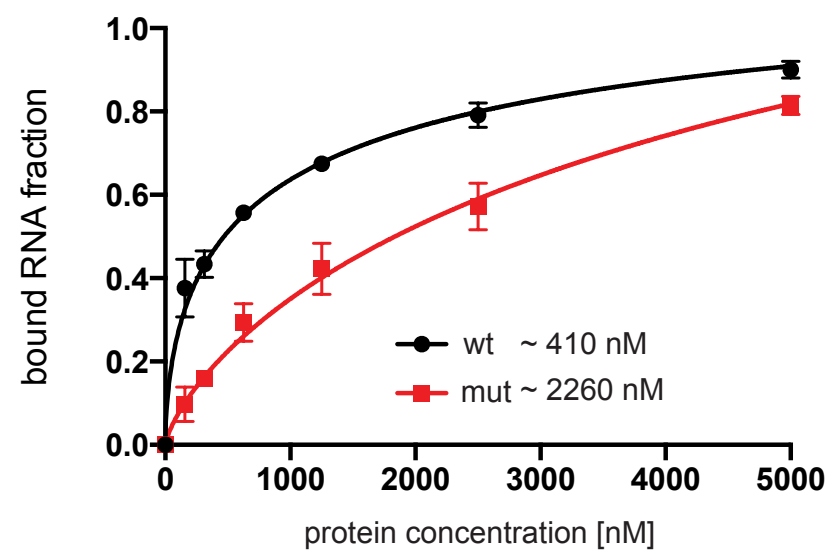

Fig 4. Mutation of the uracil-rich 5 'region in the $d$ nd1-LE reduces Tia1 binding. (A) Sequence of full length wild-type (wt) and mutant (mut) dnd1LE. Multiple uracil bases in the Tia 1 binding site (boxed) were replaced by adenines by site-directed mutagenesis (red letters). The miR-18 target is shown in blue. (B) Binding of bacterially expressed Tia1 to wild-type (wt) and mutant (mut) dnd1-LE was analyzed by electrophoretic mobility shift assays (see Figure S2B). The relative amount of complexed RNA is plotted against the individual protein concentrations using non-linear curve fitting; approximate $K_{D}$ values for wild-type and mutantdnd1-LERNAs are indicated.

Tia1 is a potential novel component of vegetal localization RNPs in $X$. laevis oocytes and, although its role during vegetal RNA localization is unclear, we found that it may function in the context of stabilizing vegetally localizing mRNAs during MZT.

\section{Discussion}

We identified the RNA binding protein Tia1 as a potential novel component of vegetal localization complexes in $X$. laevis oocytes. Tia1 directly interacts and co-localizes with vegetal LE RNAs. Ectopic expression of Tia1 in $X$. laevis embryos leads to somatic stabilization of a dnd1-LE reporter RNA and several other endogenous vegetally localizing germ cell RNAs. Co-expression of Tia1 with Dnd1 increases dnd1-LE reporter RNA stabilization.

Tia1 is an RRM-type protein that has been reported to act in the regulation of alternative splicing (Del Gatto et al., 1997; Förch et al., 2000; Zhu et al., 2003) and translation of diverse transcripts by binding to AU-rich sequence elements (Piecyk et al., 2000; Dixon et al., 2003; Kandasamy et al., 2005). Tia1 can also promote a general translational arrest in response to environmental stress by formation of stress granules (Kedersha et al., 1999; Gilks et al., 2004). Tia1 was shown to shuttle between nucleus and cytoplasm with a predominantly nuclear localization in somatic cells (Kedersha et al., 1999; Zhang et al., 2005). In X. laevis oocytes, Tia1 has been detected predominantly in the cytoplasm (Colegrove-Otero et al., 2005) and tia1 transcripts are expressed throughout embryogenesis with highest RNA levels in neural tissues (Rothé et al., 2006).

\section{Tia1, a translational regulator in oocytes?}

Although Tia1 might be a component of vegetally localizing RNPs in oocytes, we were unable to provide direct experimental evidence for an essential function in vegetal RNA transport. However, Tia1 might exert other functions on vegetal RNA localization. Tia1 has been shown to act in the translational repression of diverse mRNAs in mice (Piecyk et al., 2000; Dixon et al., 2003; Yu et al., 2003). A number of other localization complex components have been reported to function in translational repression in different biological systems (Kim-Ha et al., 1995; Colegrove-Otero et al., 2005; Hüttelmaier et al., 2005). However, tethering of Tia1 to a reporter RNA did not mediate translational repression in oocytes (data not shown), indicating that Tia1 is not sufficient for translational repression of transcripts.

The translational activity of a mutant $d n d 1$-LE reporter RNA with reduced affinity for Tia1 as compared to a wild-type dnd1-LE reporter RNA was also not affected (data not shown). Similarly, Tia1 was found to bind to the gdf1 translational element, but depletion of Tia1 from oocyte extracts did not affect translational activity of a gdf1 reporter RNA (Colegrove-Otero et al., 2005). Thus, Tia1 might not regulate the translation of dnd1 or gdf1 transcripts, or Tia1 mediated translational repression is not detectable by the reporter assays described above, as it might require other regions in the mRNA.

\section{Self aggregation of Tia1 - a role in the multimerization of localization RNPs and formation of stress granules?}

Stress granules are transient cytoplasmic aggregates of $\mathrm{mRNA}$ that contain $48 \mathrm{~S}$ translation initiation factors, poly(A)-binding protein 1, and small ribosomal subunits (reviewed in Anderson and Kedersha, 2008). Tia1 is a known component of stress granules in somatic cells, promoting their formation by self-aggregation via its prion-like C-terminal domain (Tian et al., 1991; Gilks et al., 2004). Strikingly, other known localization RNP components like Staufen 1 and Elavl proteins have been reported to be components of stress granules in other systems (Gallouzi et al., 2000; Thomas et al., 2005). Thus, localization RNPs and stress granules appear to contain overlapping components. C. elegans oocytes form large RNP granules in response to stress that contain Tia1 (Jud et al., 2008; Patterson et al., 2011), whereas, to our best knowledge, the presence of stress granules in Xenopus oocytes has not been reported to date. Nevertheless, Tia1 might promote multimerization of localization RNPs. Indeed, localization RNPs are thought to oligomerize into larger complexes that are co-transported to the vegetal cortex (reviewed in Pratt and Mowry, 2012; Xing and Bassell, 2013). OskarmRNA, for example, localizes to large granules that are translationally silent during transport to the posterior pole of Drosophila oocytes (Chekulaeva et al., 2006). Further evidence for the transport in granules containing multiple different RNA mol- 
A

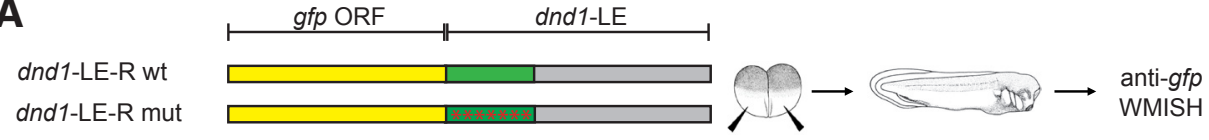

B

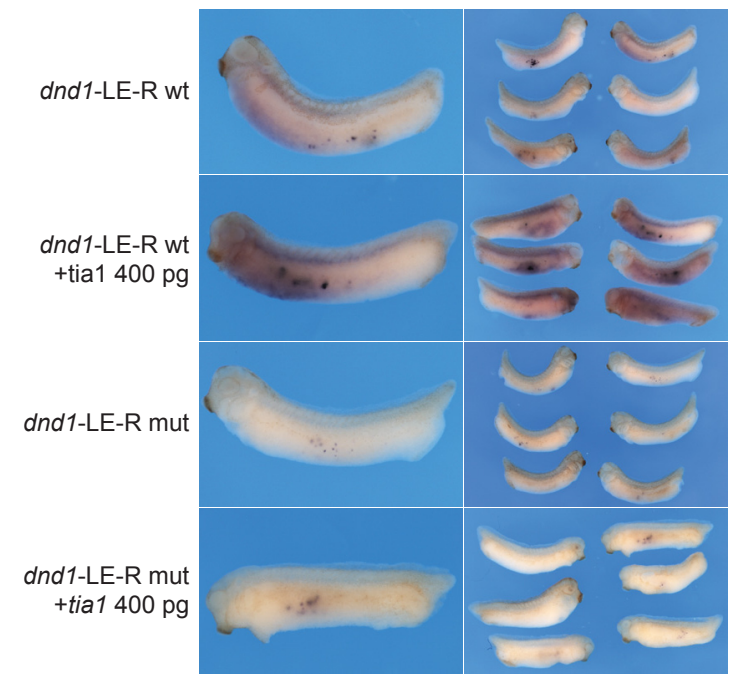

D

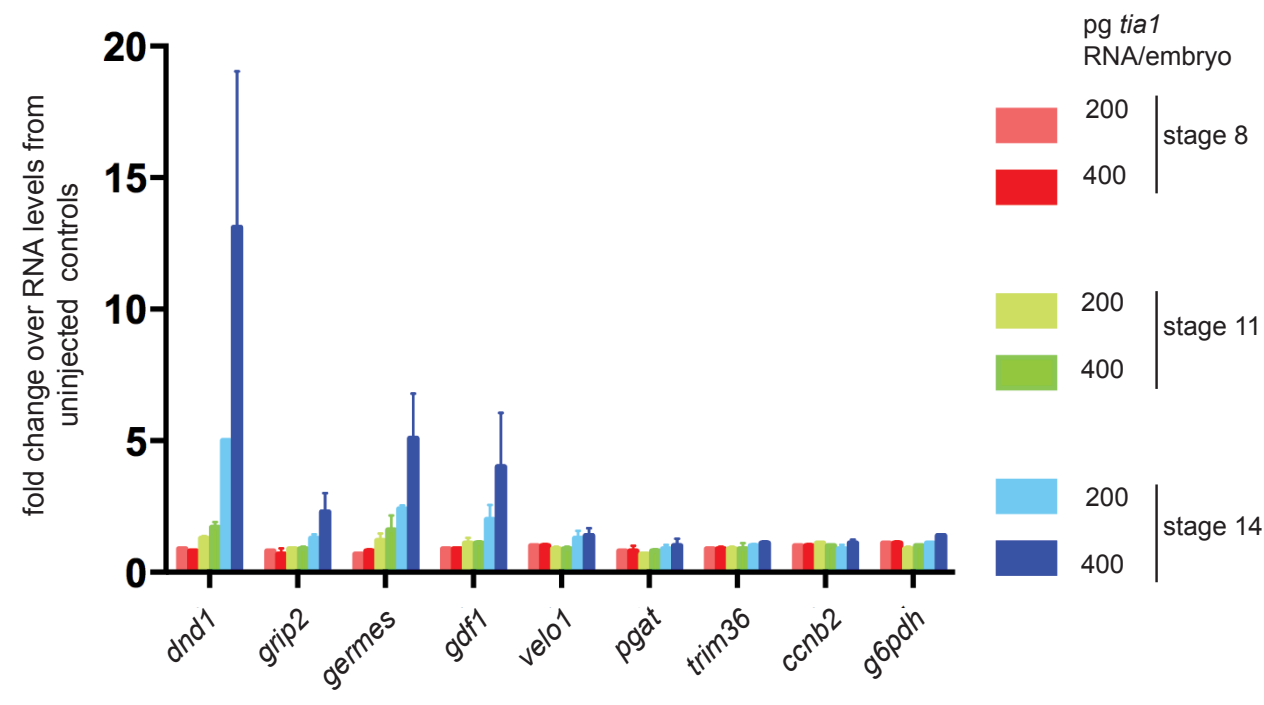

Fig 5. Somatic expression of Tia1 stabilizes injected dnd1-LE reporter RNA and endogenous localizing mRNAs. (A) Wild-type (wt) or mutant (mut) dnd1-LEreporter (dnd1-LE-R) RNAs containing the gfp open reading frame were injected into both vegetal blastomeres of 2-cell stage Xenopus embryos. Atstage 32, whole mount in situ hybridization was performed against gfp. (B) Embryos injected with wildtype or mutant dnd1-LE-reporter RNAs alone or co-injected with 400 pg RNA encoding Tia 1. (C) Quantification of dnd1-LE-reporter RNA levels as scored in the injected embryos. Mean values of 2 independent experiments are shown. Error bars indicate the standard error of the mean. (D) Fold change in RNA levels of different endogenous localizing and control mRNAs at the developmental stages indicated after overexpression of Tia 1 . Xenopus 2-cell stage embryos were injected with 200 or 400 pg tia1 RNA. Embryos were grown until stages 8,11 or 14 and subjected to total RNA extraction. RNA samples were analyzed using the $n$ Counter $\Theta$ Gene Expression assay (NanoString Technologies). The averaged fold change of selected RNAs over uninjected control embryos of two independent experiments are shown, error bars indicate the standard error of the mean.

\section{Tia1 - a function in RNA stabilization} during embryogenesis?

Over-expression of Tia 1 counteracts the somatic degradation of several maternal, vegetally localizing mRNAs in $X$. laevis embryos at MZT. Tia1 also co-localizes with these RNAs in the oocyte, suggesting that it remains bound to its RNA targets upon fertilization. Similarly, Elavl2 was also shown to bind localizing RNAs in the oocyte and to stabilize the same transcripts in the embryo (Koebernick et al., 2010). Most of the RNAs stabilized by Tia1, such as dnd1, germes and grip2, are germ cell specific, indicating that Tia1

ecules comes from studies on ASH1 and IST2 mRNAs in yeast (Lange et al., 2008). However, yet different experiments support the idea of independent localization of singular RNPs; AmruteNayak and Bullock (2012) found that individual mRNA molecules are present in distinct reconstituted Drosophila RNPs. Similarly, different dendritic mRNAs were shown to localize to distinct RNPs, and might thus contribute to a higher efficiency of temporal and spatial control of protein expression in neurons (Mikl et al., 2011). We observed that a mutant $d n d 1$-LE RNA with reduced affinity for Tia1 shows full localization capacity in Xenopus oocytes and is found to be present in similar granular structures as observed for wild-type dnd1-LE RNA (data not shown). Different localization RNP components might thus act redundantly in RNP multimerization, or the same process might be dispensable for vegetal RNA transport. might exert a specific function in the protection of germline RNAs from miR mediated decay. However, although other germ cell specific mRNAs are largely degraded during MZT (pgat, trim36), they are not affected by Tia1 overexpression, suggesting that Tia1 is involved in the stabilization of only a subset of maternally expressed germline RNAs. Tia1 seems not to be essential for the stabilization of germ cell specific transcripts, as a mutant $d n d 1$-LE reporter RNA with vastly reduced affinity for Tia1 is stable in PGCs. Thus, there must be additional proteins involved in the protection of germ cell specific transcripts, such as Elavl2 (Koebernick et al., 2010). Tia1 has been reported to be mainly expressed in neural tissue during $X$. laevis development (Rothé et al., 2006), but tia1 transcripts are detectable in $X$. laevisgerm cells as well, as revealed by RNA sequencing (our own unpublished results). Thus, germ 
A

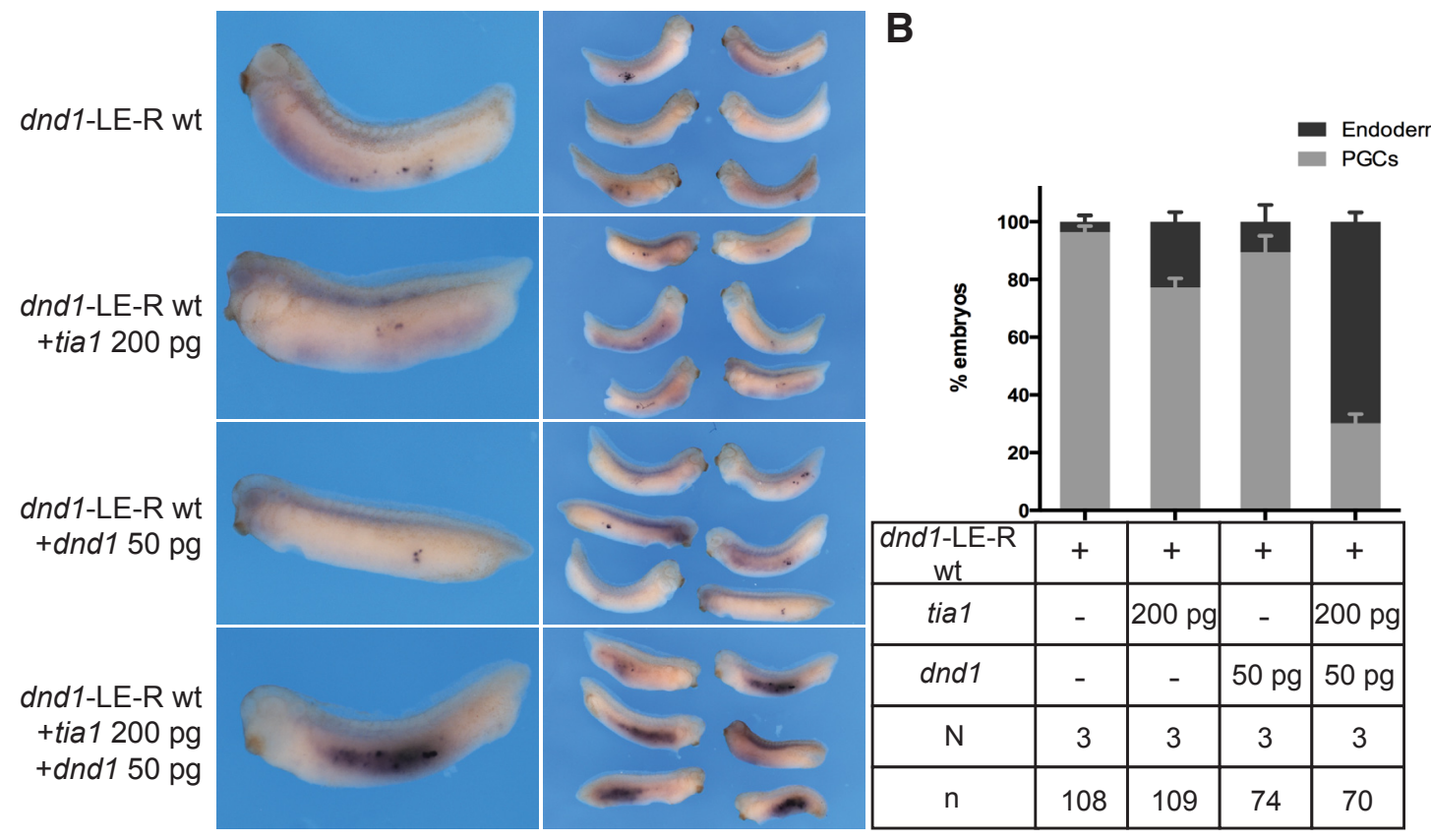

Fig 6. Tia1 synergizes with Dnd1 in the stabilization of dnd1-LE-reporter RNA in Xenopus embryos. (A) Embryos injected with gfp-dnd1-LE reporter RNA (dnd1-LE-R wt) alone or co-injected with low doses of RNA encoding either Tia 1 or Dnd1 or both. Reporter RNA levels were detected by WMISH at stage 32. Injected wild-type dnd1-LE reporter RNA alone is degraded in the soma and stable in PGCs. Over-expression of low doses of Tia 1 or Dnd1 does not stabilize dnd1-LE reporter RNA in the soma. Co-expression of same doses of Tia1 and Dnd1 leads to somatic stabilization of dnd1-LE reporter RNA. (B) Quantification of dnd1-LE reporter RNA levels scored in the injected embryos. Mean values of three independent experiments are shown, error bars indicate the standard error of the mean.

cell specific RNA protection might involve interaction of Tia1 with additional germ cell specific proteins, similar to what was shown for Elavl2 and Dnd1; even though Elavl2 is not germ cell specific, it synergizes with the germ cell specific Dnd1 in RNA stabilization.

Although TIA1 and the highly similar TIAR are suggested to act partially redundant, TIAR is essential for germ cell development in mice (Beck et al., 1998), while TIA1 knock-out mice are fully fertile (Piecyk et al., 2000). However, the differences of both proteins that enable a unique function of TIAR in germ cell development are not defined so far.

Ectopic expression of Tia1 also leads to stabilization of localizing mRNAs that are not germ cell specific, including gdf1. Although the LE of gdf1 mRNA does not mediate somatic degradation (Koebernick et al., 2010), gdf1 transcript levels decrease during MZT (Birsoy et al., 2006; Table S1-S4). Thus, gdf1 mRNA might contain miR target sites outside of the LE, or gdf1 mRNA is degraded by other mechanism than miR-mediated decay, which endogenous Tia1 seems to counteract. Maternal gdf1 transcripts seem to be essential for early development, as the antisense depletion of gdf1 mRNA in Xenopus embryos leads to gastrulation defects (Birsoy et al., 2006). Thus, Tia1 might also stabilize other maternal RNAs that are involved in specific aspects of early embryonic development other than germ cell development.

In $X$. laevis, the degradation of dnd1 mRNA during MZT appears to be mediated by miR-18 (Koebernick et al., 2010). Thus, $X$. laevis Tia1 might protect target RNAs by antagonizing miR-18 binding. Similarly, Dnd1 protein is suggested to prevent binding of miR-430 to the germline mRNAs nanos and $t d r d 7$ in zebrafish (Kedde et al., 2007). Indeed, Tia1 bind s to the 5'-part of the dnd1-LE, overlapping with the miR-18 target site, and it might thus prevent
miR-mediated RNA degradation by physically blocking the target site of miR-18. On the other hand, Tia1 could also alter the RNA structure and thereby inhibit miR binding. We also can not exclude other mechanisms to counteract miR mediated decay for example by controlling poly A tail length as suggested for Dazl (Takeda et al., 2009). Additional efforts will be required in order to clarify the mechanism of Tia1 mediated RNA stabilization.

\section{Materials and Methods}

\section{DNA cloning and protein expression}

The open reading frame of Tia1 was amplified by PCR from $X$. laevis oocyte cDNA and subcloned into EcoRI and Xhol of pCS2+Flag vector using the following primers GGAATTCTATGGAGGAAGATCTACCCAAAACG (forward), CCGCTCGAGTCATTGTGTTTGGTATCCAGC (reverse). The sequence of the Tia1 ORF cloned here is identical to the Tia1 nucleotide sequence published by Rothé et al., (2006) (NCBI accession number AJ416631), with the exception of a 9 nucleotide deletion. Celf1 and Ptbp1 expression constructs were cloned as described in Bauermeister et al., (2015). The Dnd1 expression construct is described in Koebernick et al., (2010).

For expression of recombinant proteins, the Tia1 coding region was amplified using primers containing Nhe1 and Xho1 restriction sites, and the PCR product was cloned into the expression vector pET21a (Novagen). His-tagged, recombinant protein was purified as described previously (Bauermeister et al., 2015; Git and Standart, 2002). The generation of dnd1-LE deletion fragments was as we have described earlier (Bauermeister et al., 2015). The mutant version of 5'del1 dnd1-LE was generated by sitedirected mutagenesis using the QuikChange II Site-Directed Mutagenesis Kit (Agilent technologies) following the manufacturer's instructions. For embryo injection, the mutant and wt 5'del1 dnd1-LE was amplified with primers containing Xhol and Not1 restriction sites and cloned into the GFP 
construct that was previously described (Koebernick et al., 2010).

\section{In vitro transcription}

In vitrotranscription of capped and labeled RNAs was done as described before (Bauermeister et al., 2015).

\section{Electrophoretic mobility shift assays (EMSAs)} 2015).

EMSAs were performed as previously described (Bauermeister et al.,

\section{Oocyte and embryo treatment}

Oocytes were isolated and extracts prepared as described before (Bauermeister et al., 2015). For Western blot analysis 2 oocytes or nuclei/ cytoplasm were used per lane. Oocyte injection was done essentially as described by Claussen and Pieler, 2004. For injection of RNA encoding Flag-tagged proteins, 1 to 1.5 ng capped RNA was injected into the cytoplasm of stage III oocytes in $3 \mathrm{nl}$ volume. Oocytes were incubated for 24 h at $18{ }^{\circ} \mathrm{C}$ in MBSH and homogenized. Oocytes for immunofluorescence analysis were injected and cultured as described (Bauermeister et al., 2015). Embryos were obtained according to standard procedures (Sive et al., 2000). 2-cell stage embryos were injected vegetally with varying amounts of capped RNA and 500 pg dnd1-LE reporter RNA in a volume of $4 \mathrm{nl}$ into both blastomeres, cultivated at $12.5^{\circ} \mathrm{C}$ for 6 days and fixed at stage 32-34. Embryos were processed for in situ hybridization as described previously (Harland, 1991) using digoxigenin-labeled RNA probes directed against the GFP encoding portion.

\section{Immunofluorescent staining of oocytes}

Immunostaining of oocytes was done as described (Gagnon and Mowry, 2011). The primary anti-Tia1 antibody (sc-1751, Santa Cruz) was diluted $1: 250$ and the secondary anti-goat-Alexa633 antibody (A21082, Invitrogen) was diluted 1:500 in PBT $+2 \%$ horse serum and $2 \%$ BSA. Fluorescence was visualized by confocal imaging (LSM780, Zeiss).

\section{Co-immunoprecipitations}

Co-immunoprecipitation of proteins from oocyte lysate was done as described (Bauermeister et al., 2015). Co-immunoprecipitation of Cy3labeled RNAs was performed essentially as described by Claussen et al., 2011 using anti-Flag M2 affinity gel (Sigma).

\section{Western blotting}

Protein samples were separated by SDS-PAGE and blotted onto nitrocellulose membranes. Anti-Tia1 (sc-1751, Santa Cruz) was diluted in $5 \%$ non-fat milk in TBST at $1 / 1000$ and incubated overnight at $4{ }^{\circ} \mathrm{C}$. The primary antibodies anti-Elavl (anti-HuR; sc-5261; Santa Cruz Biotechnology, Inc.), anti-Igf2bp3 (Vg1RBP) (Zhang et al., 1999), anti-Stau1 (Allison et al., 2004), anti-Hnrnpab (40LoVe) (Czaplinski et al., 2005) as well as secondary antibodies were employed and detection performed as described (Bauermeister et al., 2015).

\section{Quantitative multiplex RNA analysis}

Injected $X$. laevis embryos were grown until stages 8,11 or 14 and total RNA was extracted from a pool of five embryos using peqGOLD TriFast (PEQLAB) after manufacturer's instructions followed by DNase I treatment (Thermo Scientific). RNA samples were analyzed using the nCounter ${ }^{\circledR}$ Gene Expression assay (NanoString Technologies) following the manufacturer's instructions. $500 \mathrm{ng}$ of each RNA sample were incubated for 16 h at $65^{\circ} \mathrm{C}$ in hybridization buffer containing the CodeSet. Data acquisition was done by imaging on a digital analyzer. Raw counts were normalized using internal positive controls, and target genes were normalized to the internal housekeeping genes odc, gapdh, laminB1 and $h 4$. For background correction, the mean and two times the standard deviation of the 8 internal negative control counts (mean $+2 \times \mathrm{SD}$ ) was subtracted from each target gene count. For data processing, the nSolver software v1.1 (NanoString Technologies) was used.

\section{Acknowledgments}

The authors would like to thank $H$. Urlaub for tandem mass spectrometry, J. Yisraeli, N. Standart, K. Czaplinski and I. W. Mattaj for antibodies and M. Dornwell for excellent technical assistance.

\section{References}

ALLISON R, CZAPLINSKI K, GIT A, ADEGBENRO E, STENNARD F, HOULISTON E, STANDART N (2004). Two distinct Staufen isoforms in Xenopus are vegetally localized during oogenesis. RNA 10: 1751-1763.

AMRUTE-NAYAK M, BULLOCK SL (2012). Single-molecule assays reveal that RNA localization signals regulate dynein-dynactin copy number on individual transcript cargoes. Nat Cell Biol 14: 416- 423.

ANDERSON P, KEDERSHAN (2008). Stress granules: the Tao of RNA triage. Trends Biochem Sci 33: 141-150.

ARTHUR PK, CLAUSSEN M, KOCH S, TARBASHEVICH K, JAHN O, PIELER T (2009). Participation of Xenopus Elr-type proteins in vegetal mRNA localization during oogenesis. J Biol Chem 284: 19982-19992.

BAUERMEISTER D, CLAUSSEN M, PIELER T (2015). A novel role for Celf1 in vegetal RNA localization during Xenopus oogenesis. Dev Biol 405: 214-224. (doi:10.1016/j.ydbio.2015.07.005).

BECK AR, MEDLEY QG, O'BRIEN S, ANDERSON P, STREULI M (1996). Structure, tissue distribution and genomic organization of the murine RRM-type RNA binding proteins TIA-1 and TIAR. Nucleic Acids Res 24: 3829-3835.

BECK AR, MILLER IJ, ANDERSON P, STREULI M (1998). RNA-binding protein TIAR is essential for primordial germ cell development. Proc Natl Acad Sci USA 95: 2331-2336.

BIRSOY B, KOFRON M, SCHAIBLE K, WYLIE C, HEASMAN J (2006). Vg1 is an essential signaling molecule in Xenopus development. Development 133: 15-20.

BUSHATI N, STARKA, BRENNECKE J, COHEN SM (2008). Temporal Reciprocity of miRNAs and Their Targets during the Maternal-to-Zygotic Transition in Drosophila. Curr Biol 18: 501-506.

CHEKULAEVAM, HENTZE MW, EPHRUSSIA (2006). Bruno acts as a dual repressor of oskar translation, promoting mRNA oligomerization and formation of silencing particles. Cell 124: 521-533.

CLAUSSEN M, TARBASHEVICH K, PIELER T (2011). Functional dissection of the RNA signal sequence responsible for vegetal localization of XGrip2.1 mRNA in Xenopus oocytes. RNA Biol 8: 873-882.

CLAUSSEN M, PIELERT (2004). Xvelo1 uses a novel 75-nucleotide signal sequence that drives vegetal localization along the late pathway in Xenopus oocytes. Dev Biol 266: 270-284.

COLEGROVE-OTERO LJ, DEVAUX A, STANDART N (2005). The Xenopus ELAV protein ElrB represses Vg1 mRNA translation during oogenesis. Mol Cell Biol 25: 9028-9039.

COTE CA, GAUTREAU D, DENEGRE JM, KRESS TL, TERRY NA, MOWRY KL (1999). A Xenopus protein related to hnRNP I has a role in cytoplasmic RNA localization. Mol Cell 4: 431-437.

CZAPLINSKI K, KÖCHER T, SCHELDER M, SEGREF A, WILM M, MATTAJ IW (2005). Identification of 40LoVe, a Xenopus hnRNP D family protein involved in localizing a TGF-beta-related mRNA during oogenesis. Dev Cell 8: 505-515.

DEL GATTO F, PLET A, GESNEL M-C, FORT C, BREATHNACH R (1997). Multiple interdependent sequence elements control splicing of a fibroblast growth factor receptor 2 alternative exon. Mol Cell Biol 17: 5106-5116.

DEMBER LM, KIM ND, LIU KQ, ANDERSON P (1996). Individual RNA recognition motifs of TIA-1 and TIAR have different RNA binding specificities. $J$ Biol Chem 271: $2783-2788$

DIXON DA, BALCH GC, KEDERSHA N, ANDERSON P, ZIMMERMAN GA, BEAUCHAMPRD, PRESCOTT SM (2003). Regulation of cyclooxygenase-2 expression by the translational silencer TIA-1. J Exp Med 198: 475-481.

FÖRCH P, PUIG O, KEDERSHA N, MARTÍNEZ C, GRANNEMAN S, SÉRAPHIN B, ANDERSON P, VALCÁRCEL $J(2000)$. The apoptosis-promoting factor TIA-1 is a regulator of alternative pre-mRNA splicing. Mol Cell 6: 1089-1098.

Gagnon JA, Mowry KL (2011). Visualization of mRNALocalization in Xenopus Oocytes. Methods Mol Biol 714: 71-82.

GALLOUZI I-E, BRENNAN CM, STENBERG MG, SWANSON MS, EVERSOLE A, 
MAIZELS N, STEITZ JA (2000). HuR binding to cytoplasmic mRNA is perturbed by heat shock. Proc Natl Acad Sci USA 97: 3073-3078.

GILKS N, KEDERSHA N, AYODELE M, SHEN L, STOECKLIN G, DEMBER LM, ANDERSON P (2004). Stress granule assembly is mediated by prion-like aggregation of TIA-1. Mol Biol Cell 15: 5383-5398.

GIRALDEZ AJ, MISHIMA Y, RIHEL J, GROCOCK RJ, VAN DONGEN S, INOUE K, ENRIGHT AJ, SCHIER AF (2006). Zebrafish MiR-430 promotes deadenylation and clearance of maternal mRNAs. Science 312: 75-79.

GIT A, STANDART N (2002). The KH domains of Xenopus Vg1RBP mediate RNA binding and self-association. RNA 8: 1319-1333.

HARLAND RM (1991). In situ hybridization: an improved whole-mount method for Xenopus embryos. Methods Cell Biol 36: 685-695.

HAVIN L, GIT A, ELISHA Z, OBERMAN F, YANIV K, SCHWARTZ SP, STANDART N, YISRAELI JK (1998). RNA-binding protein conserved in both microtubule- and microfilament-based RNA localization. Genes Dev 12: 1593-1598.

HORVAY K, CLAUSSEN M, KATZER M, LANDGREBE J, PIELERT (2006). Xenopus Dead end mRNA is a localized maternal determinant that serves a conserved function in germ cell development. Dev Biol 291: 1-11.

HÜTTELMAIER S, ZENKLUSEN D, LEDERER M, DICTENBERG J, LORENZ M, MENG X, BASSELL GJ, CONDEELIS J, SINGER RH (2005). Spatial regulation of $\beta$-actin translation by Src-dependent phosphorylation of ZBP1. Nat Cell Biol 438: 512-515.

JUD MC, CZERWINSKI MJ, WOOD MP, YOUNG RA, GALLO CM, BICKEL JS, PETTY EL, MASON JM, LITTLE BA, PADILLA PA, SCHISA JA (2008). Large P body-like RNPs form in C. elegans oocytes in response to arrested ovulation, heat shock, osmotic stress, and anoxia and are regulated by the major sperm protein pathway. Dev Biol 318: 38-51.

KANDASAMYK, JOSEPH K, SUBRAMANIAM K, RAYMOND JR, THOLANIKUNNEL $B G$ (2005). Translational control of $\beta 2$-adrenergic receptor mRNAby T-cell-restricted intracellular antigen-related protein. J Biol Chem 280: 1931-1943.

KEDDE M, STRASSER MJ, BOLDAJIPOUR B, VRIELINK JAF, SLANCHEV K, LE SAGE C, NAGEL R, VOORHOEVE PM, VAN DUIJSE J, ØROM UA, LUND AH, PERRAKIS A, RAZ E, AGAMI R (2007). RNA-binding protein Dnd1 inhibits microRNA access to target mRNA. Cell 131: 1273-1286.

KEDERSHA NL, GUPTA M, LI W, MILLER I, ANDERSON P (1999). RNA-binding proteins TIA-1 and TIAR link the phosphorylation of elF-2 $\alpha$ to the assembly of mammalian stress granules. J Cell Biol 147: 1431-1442.

KIM-HA J, KERR K, MACDONALD PM (1995). Translational regulation of oskar mRNA by bruno, an ovarian RNA-binding protein, is essential. Cell 81: 403-412.

KING M, MESSITT T, MOWRY KL (2005). Putting RNAs in the right place at the right time: RNA localization in the frog oocyte. Biol Cell 97: 19-33.

KOEBERNICK K, LOEBER J, ARTHUR PK, TARBASHEVICH K, PIELER T (2010). Elr-type proteins protect Xenopus Dead end mRNA from miR-18-mediated clearance in the soma. Proc Natl Acad Sci USA 107: 16148-16153.

LANGE S, KATAYAMA Y, SCHMID M BURKACKY O, BRAUCHLE C, LAMB DC, JANSEN RP (2008). Simultaneous transport of different localized mRNA species revealed by live-cell imaging. Traffic 9: 1256-1267.

LANGLEY AR, SMITH JC, STEMPLE DL, HARVEY SA (2014). New insights into the maternal to zygotic transition. Development 141: 3834-3841.

LOEBER J, CLAUSSEN M, JAHN O, PIELER T (2010). Interaction of 42Sp50 with the vegetal RNA localization machinery in Xenopus laevis oocytes. FEBS J 277: 4722-4731.

LÓPEZDE SILANESI, GALBÁNS, MARTINDALE JL, YANG X, MAZAN-MAMCZARZ
K, INDIG FE, FALCO G, ZHAN M, GOROSPE M (2005). Identification and functional outcome of mRNAs associated with RNA-binding protein TIA-1. Mol Cell Biol 25: 9520-9531.

LUND E, LIU M, HARTLEY RS, SHEETS MD, DAHLBERG JE (2009). Deadenylation of maternal mRNAs mediated by miR-427 in Xenopus laevis embryos. RNA 15 2351-2363.

MIKL M, VENDRA G, KIEBLER MA (2011). Independent localization of MAP2, CaMKIl $\alpha$ and $\beta$-actin RNAs in low copy numbers. EMBO Rep 12: 1077-1084.

PATTERSON JR, WOOD MP, SCHISA JA (2011). Assembly of RNP granules in stressed and aging oocytes requires nucleoporins and is coordinated with nuclear membrane blebbing. Dev Biol 353: 173-185.

PIECYK M, WAX S, BECK AR, KEDERSHA N, GUPTA M, MARITIM B, CHEN S, GUEYDAN C, KRUYS V, STREULI M, ANDERSON P (2000). TIA-1 is a translational silencer that selectively regulates the expression of TNF-alpha. EMBO J 19: 4154-4163.

PRATT CA, MOWRY KL (2012). Taking a cellular road-trip: mRNA transport and anchoring. Curr Opin Cell Biol 25: 1-8.

ROTHÉ F, GUEYDAN C, BELLEFROID E, HUEZ G, KRUYS V (2006). Identification of FUSE-binding proteins as interacting partners of TIA proteins. Biochem Biophys Res Commun 343: 57-68.

Sive HL, Grainger RM, Harland RM (2000). Early development of Xenopus laevis: a laboratory manual. Cold Spring Harbor, NY: Cold Spring Harbor Laboratory Press, NY.

TADROS W, LIPSHITZ HD (2009). The maternal-to-zygotic transition: a play in two acts. Development 136: 3033-3042.

TAKEDAY, MISHIMAY, FUJIWARAT, SAKAMOTOH, INOUE K (2009). DAZL relieves miRNA-mediated repression of germline mRNAs by controlling poly $(A)$ tail length in zebrafish. PLoS One 4: e7513.

THOMAS MG, TOSAR LJM, LOSCHI M, PASQUINI JM, CORREALE J, KINDLER S, BOCCACCIO GL (2005). Staufen recruitment into stress granules does not affect early mRNA transport in oligodendrocytes. Mol Biol Cell 16: 405-420.

TIAN Q, STREULI M, SAITO H, SCHLOSSMAN SF, ANDERSON P (1991). A polyadenylate binding protein localized to the granules of cytolytic lymphocytes induces DNA fragmentation in target cells. Cell 67: 629-639.

XING L, BASSELLGJ (2013). mRNA localization: an orchestration of assembly, traffic and synthesis. Traffic 14: 2-14.

YOON YJ, MOWRY KL (2004). Xenopus Staufen is a component of a ribonucleoprotein complex containing Vg1 RNA and kinesin. Development 131: 3035-3045.

YU Q, COK SJ, ZENG C, MORRISON AR (2003). Translational repression of human matrix metalloproteinases-13 by an alternatively spliced form of T-cell-restricted intracellular antigen-related protein (TIAR). J Biol Chem 278: 1579-1584.

ZHANG Q, YANIV K, OBERMAN F, WOLKE U, GIT A, FROMER M, TAYLOR WL, MEYER D, STANDART N, RAZ E, YISRAELI JK (1999). Vg1 RBP intracellular distribution and evolutionarily conserved expression at multiple stages during development. Mech Dev 88: 101-106.

ZHANG T, DELESTIENNE N, HUEZ G, KRUYS V, GUEYDAN C (2005). Identification of the sequence determinants mediating the nucleo-cytoplasmic shuttling of TIAR and TIA-1 RNA-binding proteins. J Cell Sci 118: 5453-5463.

ZHOU Y, KING ML (2004). Sending RNAs into the future: RNA localization and germ cell fate. IUBMB Life 56: 19-27.

ZHU H, HASMAN RA, YOUNG KM, KEDERSHA NL, LOU H (2003). U1 SnRNP. dependent function of TIAR in the regulation of alternative RNA processing of the human calcitonin/CGRP pre-mRNA. Mol Cell Biol 23: 5959-5971. 


\section{Further Related Reading, published previously in the Int. J. Dev. Biol.}

Intracellular localizations of the Dead End protein in Xenopus primordial germ cells Ayaka Taguchi, Kenji Watanabe and Hidefumi Orii

Int. J. Dev. Biol. (2014) 58: 793-798

http://dx.doi.org/10.1387/ijdb.140308ho

Germes is involved in translocation of germ plasm during development of Xenopus primordial germ cells.

Yamaguchi T, Taguchi A, Watanabe K, Orii $\mathrm{H}$.

Int J Dev Biol. (2013) 57: 439-443.

Centroid, a novel putative DEAD-box RNA helicase maternal mRNA, is localized in the mitochondrial cloud in Xenopus laevis oocytes.

Kloc M, Chan AP.

Int J Dev Biol. (2007) 51: 701-6

Delivery of germinal granules and localized RNAs via the messenger transport organizer pathway to the vegetal cortex of Xenopus oocytes occurs through directional expansion of the mitochondrial cloud.

Wilk K, Bilinski S, Dougherty MT, Kloc M.

Int J Dev Biol. (2005) 49: 17-21.

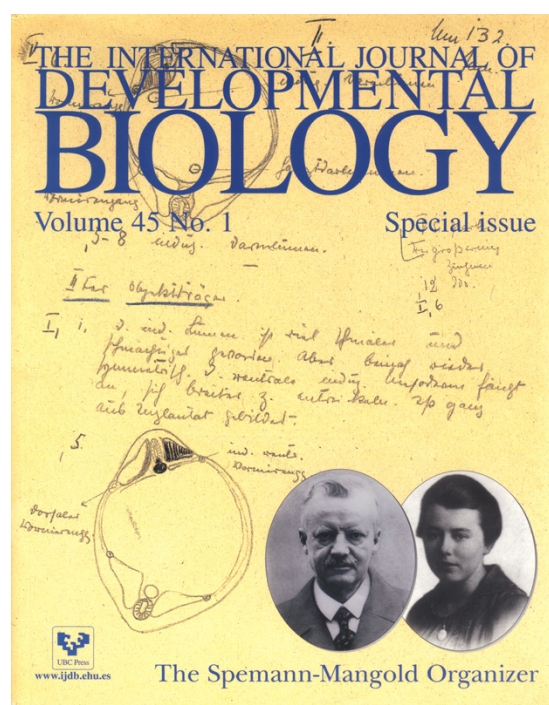

5 yr ISI Impact Factor $(2013)=2.879$
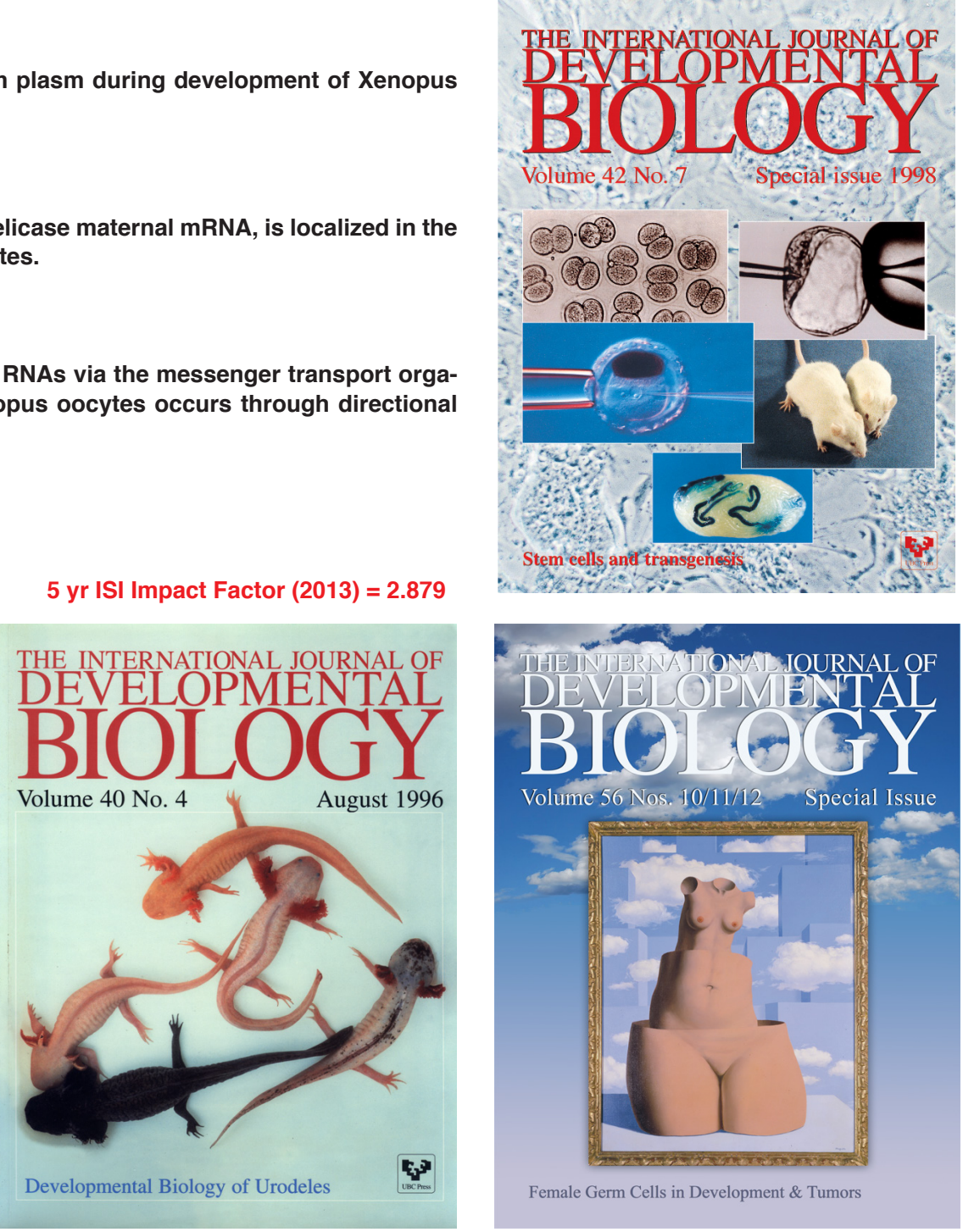

Volume 56 Nos 10/11/12 - Special Issue

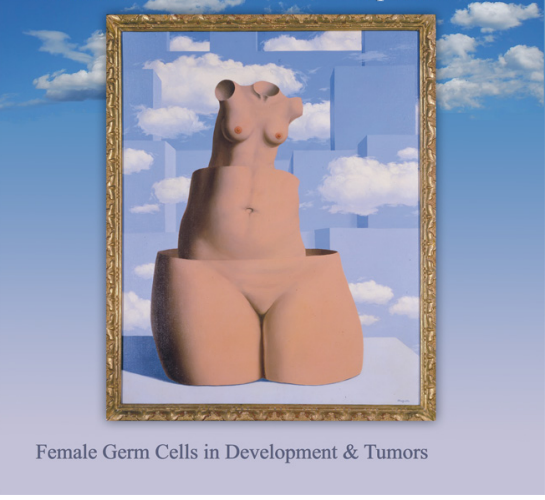

